\title{
Assessment of Engineering Properties of Artificial Aggregate Prepared From Canal Silt
}

\author{
Safdar Iqbal ${ }^{1}$, Beenish Jehan ${ }^{2}$, Fasih Ahmed Khan ${ }^{3}$, Hassan Nasir ${ }^{4}$ \\ (Received October 05, 2018; Revised November 30, 2018; Accepted December 11, 2018)
}

DOI: $10.33317 /$ SSURJ.V8.I2.73

\begin{abstract}
In this research the canal silt from the Kabul River Canal was recycled to manufacture artificial aggregate. For making artificial aggregates three batches were prepared each of dry weight of $100 \mathrm{~kg}$. The composition of artificial aggregate is Polyvinyl Alcohol (PVA), Ordinary Portland Cement (OPC) and Silt was mixed in different proportions (by weight). Three batches were made having values of PVA varying from 0,1 and 2 percent, cement content was 20,19 and 18 percent respectively, and the quantity of silt used was kept constant $(80 \%)$ in each batch. Samples were prepared from these three different batches and were cured for 28 days. After completion of the curing time, they were crushed to get the desired course aggregate. A number of tests were performed to check the viability of artificial aggregates for being used as a lightweight aggregate. Shape and particles size distribution properties of artificial aggregates were as that of the natural aggregate but not satisfactory at high silt content. The reductions in the specific gravity of the artificial aggregate were also observed compared to natural aggregates.
\end{abstract}

Index Terms- Artificial Aggregates, Canal Silt, Coarse Aggregates, Lightweight Aggregates, Polyvinyl Alcohol (PVA).

\section{INTRODUCTION}

Sedimentation in the Kabul River Canal (Peshawar) has become a major problem. The discharge capacity of the Canal has been reduced and the chances of overflowing in critical situations have increased. Cleaning of the sediments from canal require huge resources and the silt obtained after cleaning the reservoir not only will be wasted but will also cause pollution. In order to prevent pollution and reduce the cost of the cleaning reservoir, the silt is needed to be used beneficially to generate some revenue.

The reuse of canal silt is an economical and environmental substitute. Over high-temperature sintering and hydration, the canal silt is made, composed of lightweight aggregate. This lightweight is thenused as a low weight aggregate . Based on these studies, this research aimed to use canal silt as recycling waste material to help reduce environmental pollution.

Further, this research made a comparison of physical properties of artificial aggregates with natural aggregates like water absorption, fineness modlus, loss abrasion value, and sieve analysis.

\section{RESEARCH OBJECTIVE}

The objectives of this study are as follows:

- To recycle the waste canal silt.
- To check the behavior of artificial aggregates with increased Polyvinyl Alcohol (PVA) quantity.

- To comparehe physical properties of artificial aggregates with natural aggregates.

- By using the silt in the manufacture of the artificial aggregates, revenue can be produced with the expense of a little capital investment.

- To produce a lightweight aggregate that is suitable for the manufacture of lightweight concrete.

\section{LITERATURE REVIEW}

Artificial aggregates have been prepared by using many raw materials and methods, each one has its own advantages and disadvantages. Some of the relevant studies are reported below:

A research based on development of ambient temperature procedure for the manufacturing of artificial aggregates. The authors collected silt samples from aggregate recycling plants. The artificial aggregates were newly manufactured from sand, silt and a bonding material PVA. The mix was made of $2 \%$ PVA, Ordinary Portland Cement (OPC) of $18 \%$ and s ilt $80 \%$. This was passed through $6.25 \mathrm{~mm}$ sieve and the particles obtained were pan pelletized. The samples were cured for 28 days to obtain sufficient strength. The numerous combinations of cylindrical samples were obtained from sand, silt, PVA and OPC. These samples were tested in the laboratory after 28 days of curing. The study reported that increasing the OPC and PVA contents result in aggregates, with increased strength [1]. Three researchers formed aggregates by using silt, Metakaolin, and PDF. A series of three experiments were performed as given below:

a) Optimizing by using silt.

b) Meta-kaolin and silt.

c) PDF and silt.

The Geo-polymer samples contained dried powder materials with highly alkaline Sodium Silicate activating solution. Initially, Sodium Hydro Oxide $(\mathrm{NaOH})$ was dissolved in distilled water. Exothermic reactions occur and high amount of temperature was released. The solution is then cooled down up to room temperature and then Sodium Silicate solution was added. The dry material was mixed with, activating solution, for 15 minutes. The Geo-polymer samples have an adhesive property to increase bonding properties of other materials. The research presented that silt produced from the aggregate and leftover washing plants can be usefully reused using Geopolymerization for the manufacture of aggregates. The

\footnotetext{
${ }^{1}$ Graduate Student, CECOS University of I.T and Emerging Sciences, Peshawar, Pakistan. safdariqbal006@gmail.com.

${ }^{2}$ Assistant Professor, CECOS University of I.T and Emerging Sciences, Peshawar, Pakistan. beenish@cecos.edu.pk

${ }^{3}$ Lecturer, Department of Civil Engineering, University of Engineering \&Technology, Peshawar, Pakistan. fasihahmad@uetpeshawar.edu.pk

${ }^{4}$ Associate Professor, CECOS University of I.T and Emerging Sciences, Peshawar, Pakistan. hassannasir@cecos.edu.pk
} 
mechanical behavior of the final products depends on configuration and curing conditions. Viable application of Geo-polymerization for the behavior of silt is control by the high primary water content. This can overcome by mixing silt with a water reducing agent such as Meta-kaolin. PVA was used as a bonding material in this research, reported to increase the adhesive properties of silt content with other material [2].

In another research study the authors obtained artificial aggregates from the fine sediments in the reservoir. The fine sediments were collected from Shipmen Reservoir located in Northern Taiwan by using theSintering Technique. The main apparatus used was Rotary Kiln, in which the samples were heated through the sequential process. At the beginning the temperature was $100-150{ }^{\circ} \mathrm{C}$ and then increase gradually upto $500-700{ }^{\circ} \mathrm{C}$ and at last the temperature reached to $1100-1150$ ${ }^{0} \mathrm{C}$. The manufactured aggregates of relative densities ranged from $1.011 .38 \mathrm{~g} / \mathrm{cm} 3$. The crushing strength and physical properties of the sedimentary Lightweight Aggregate (LWA) were more preferable than that of the available LWA in the market. The research results show that the sedimentary LWA can help as an aggregate source for structural concrete [3].

A research was conducted to study the effect of Taichung Harbor sediments and local reservoir sediments on the artificial aggregates when used in various proportions. The sediment samples collected from the Taichung Harbor (Second largest port in Taiwan) were mixed with local canal sediment at a different ratio to manufacture LWA at the temperature of 1050,1100 and $1150{ }^{\circ} \mathrm{C}$. The LWA of bulk density 0.49 $\mathrm{gm} / \mathrm{cm}^{3}$ for 5000 -psi sample was found at $1150{ }^{\circ} \mathrm{C}$ temperature [4].

In one study some researchers prepared artificial aggregates from granulated Reactive Silica Powders. The authors examined the effect of LWA concrete with the artificial aggregates constructed on granulatedReactive Silica Powder . The genetic formula of artificial aggregates constructed on granulated reactive silica powder is "SIO2- $\mathrm{ROH}^{\circ}$. The artificial aggregates constructed on granulated Reactive Silica Powder contain the following raw material composition:

- Three types of Portland cement.

- Chalk.

- Hydrated Lime.

- Quicklime.

- Sodium Fluorosilicate.

- Sodium Silicates.

- Sodium Hydroxide.

The authors formulated the viability of the production of artificial aggregates constructed ongranulated Reactive Silica Powders, which will adapt to intermingle with cementitious matrix and beneficiate the interaction region in the LWA concretes [5].

Some other studies were conducted to successfully create LWA, from different materials. In one study the researchers created LWA from mining and industrial wastes [6]. In another study some researchers used fly ash to create LWA successfully [7].

A research study was conducted, which focused on utilizing materials like waste stone sludge and waste silt, obtained from slab stone processing and waste silt from aggregate washing plants. These materials were recycled to manufacture artificial aggregate. The fine-powdered stone sludge was mixed with waste silt of larger particle size. The vibratory compaction was applied for good water permeability, resulting in a smaller amount of solidifying agent being used. The mix proportion of waste stone sludge to waste silt was 35:50, which produced artificial aggregate of more compact structure with water absorption rate below $0.1 \%$. In addition, curing for 28 days doubled the compressive strength [8].

\section{MATERIAL AND METHODS}

\section{A. Polyvinyl Alcohol (PVA)}

Polyvinyl alcohol (PVA, PVOH) is an artificial polymer, which is water-soluble. It is widely used as a coating and adhesive agent. It is mostly used in paper industries, textiles, and a pharmaceutical market. It is a white powder, having no odor and is not toxic. It helps in film forming and is occasionally delivering as drops or as a mixture in water. It has adhesive and emulsifying behaviors, ductile, flexible and is more resilient to grease and oil. The Poisson's ratio of PVA is between $0.42-0.48$.

\section{B. Silt}

Granular materials whose particles size is between sand and clay as known is silt. It is solid dust like sediment transported by wind, ice, and water. The mineral origin of silt is feldspar and quartz. Silt made-up of rock and mineral which is approximately $0.005 \mathrm{~cm}$ large in size. When rocks eroded or worn away by ice and water, silt formed and transported with rain water and wind. Silt is slippery when mixed in water and not grainy or rocky.

\section{Ordinary Portland Cement (OPC)}

Portland cement, the most common type of cement, is a basic ingredient of concrete, mortar, stucco, and non-specialty grout. Several types of Portland cement are available. The most commonly called, Ordinary Portland Cement (OPC). Itis mostly grey in color, but white Portland cement is also available.

\section{Mix Design}

For the preparation of the aggregates, the three main constituents were mixed in an appropriateweight proportions. Here the three different batches were cast as shown in the Table. I.

Table I: Three-Batch Mix Proportion by Weight

\begin{tabular}{|l|c|c|c|}
\hline \multicolumn{1}{|c|}{ Material } & Batch-1 & Batch-2 & Batch-3 \\
\hline $\begin{array}{l}\text { Polyvinyl Alcohol } \\
\text { (PVA) }\end{array}$ & $0 \%$ & $1 \%$ & $2 \%$ \\
\hline $\begin{array}{l}\text { Ordinary Portland } \\
\text { Cement }\end{array}$ & $20 \%$ & $19 \%$ & $18 \%$ \\
\hline Silt & $80 \%$ & $80 \%$ & $80 \%$ \\
\hline Total dry weight & $100 \mathrm{~kg}$ & $100 \mathrm{~kg}$ & $100 \mathrm{~kg}$ \\
\hline
\end{tabular}

\section{E. Experimental Program}

The artificial aggregates formed, were then subjected to various tests to test their general properties. Following tests were performed on the artificial aggregates as seen in Table II. 
Table II: Experimental Program for the Test

\begin{tabular}{|c|l|c|}
\multicolumn{4}{|c}{ Table II: Experimental Program for the Test } \\
\hline S/No & \multicolumn{1}{|c|}{ Test } & ASTM Standard \\
\hline 1. & Impact of the aggregate value & ASTM-C 39 \\
\hline 2. & Aggregate Abrasion Test & ASTM (C0131) \\
\hline 3. & Sieve Analysis & ASTM-C642 \\
\hline 4. & Water Absorption test & ASTM C0127 \\
\hline
\end{tabular}

All three batches are rectangular in shapes whose dimensions are shown in Table III.

Table III: The Dimension of Rectangular Batches

\begin{tabular}{|l|c|c|c|}
\hline Name of Batches & Length & Width & Thickness \\
\hline Batch-1 & 12 inches & 8 inches & 4 inches \\
\hline Batch-2 & 12 inches & 8 inches & 4 inches \\
\hline Batch-3 & 12 inches & 8 inches & 4 inches \\
\hline
\end{tabular}

The rectangular batches were cured and crushed into coarse aggregates which are shown in Fig. 1(a) and Fig. 1(b).

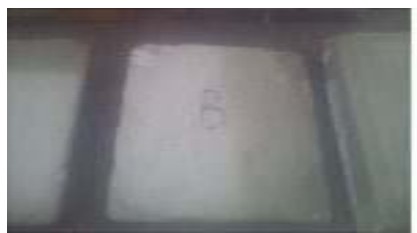

(a)

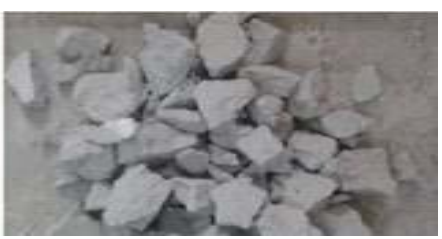

(b)
Fig. 1: Artificial Aggregates Curing and Crushing Process: a) Prepared Cubes under Curing Process; b) Crushed Artificial Aggregate

\section{F. Preparing the solution of $P V A$}

PVA was added slowlin water,while stirring for enough decentralization at the temperature that can affect the dissolving periodand swelling before heating. The average alcoholic form of PVA is gained at a temperature of above 80$90{ }^{\circ} \mathrm{C}$, within a time frame of 30 to 60 minutes almost. During dissolution, stirring confirms that the temperature does not increase rapidly.

\section{G. Manufacturing of the Aggregates}

Three batches were prepared as per the mix design, shown earlier in Table I.

- First of all the PVA is dissolved in water.

- A solution of PVA was then thoroughly mixed with OPC and Silt.

- The rectangular block is shown in Fig. 1(a) was made by using mixture prepared.

- $\quad$ The rectangular block was placed for curing for 28 days.

- The rectangular block was crushed to get the desired coarse aggregates as shown in Fig. 1(b).

\section{RESULTS AND DISCUSSIONS}

\section{A. Impact of aggregate value (ASTM C-39)}

Impact of aggregate value is the percentage loss of particles passing through $2.36 \mathrm{~mm}$ sieve by the application of the load by means of 15 blows of standard hammer and dropping, considered on definite test condition. As shown in Fig. 2, the addition of PVA in the mixture improves the loss of particles from the aggregate. The mixture without PVA has more loss of particles. Impact value of artificial aggregates is found to be satisfactory, which suggest that they can be used where they are to be subjected to repeated loadings.

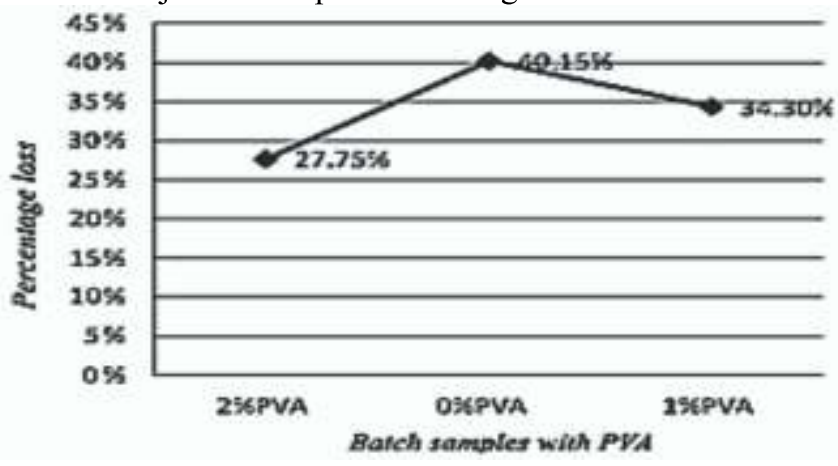

Fig. 2: Impact Value of Artificial Aggregates

\section{B. Aggregate Abrasion Test (ASTM C 131)}

Abrasion test mostly used to specify how the aggregates are tough (durable) and abrasion (scrape) properties. The confrontation of small size coarse aggregates, by a brasion and impact, in the Los Angeles Machine, is shown in Fig. 3. The addition of PVA has improved the abrasion characteristic of the aggregate. Los Angeles abrasion value of artificial aggregates is $44 \%$ which suggest it can be used in "Water bound macadam sub base course" for which limit is $60 \%$. The standard Los Angeles abrasion test is AASHTO T 96 or ASTM C 131.

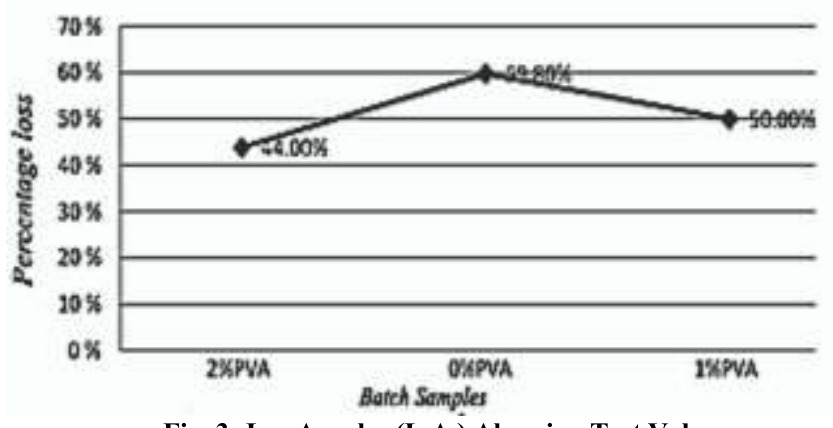

Fig. 3: Los Angeles (L.A.) Abrasion Test Values

\section{Sieve Analysis (ASTM C-642)}

Fineness modulus (FM) is a numerical digit found by adding the total percentage of the sample of an aggregate recollected on each of definite sequences of sieves and dividing the sum by 100 . Fine aggregates FM value is in between $2.00-4.00$, and coarse aggregates smaller than $38.1 \mathrm{~mm}$ range from 6.50 to 8.00 is shown in Fig. 4. Sieve analysis of the artificial aggregates provides a good result. For a sample with $2 \%$, PVA contains moderate sizes of particles (both coarse and fine aggregate).

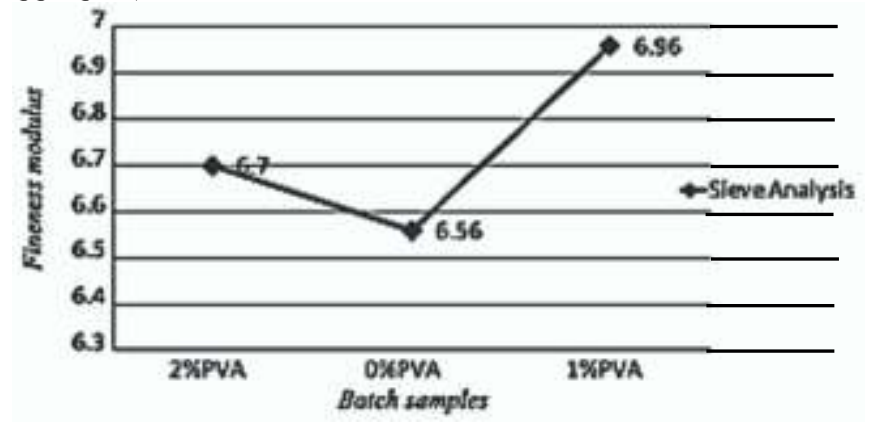

Fig. 4: Modulus by Sieve Analysis 


\section{Water Absorption test (ASTM C-127)}

With the increase of PVA in the mixture, the value of water absorption decreased with considerable quantity. The value of water absorption was on the higher side when compared with natural aggregate. Water absorption of artificial aggregates is around $10 \%$, which is greater than the maximum permissible value for aggregates. It should not be used in concrete, as it will absorb water from the mix and result in low strength as shown in Fig. 5.

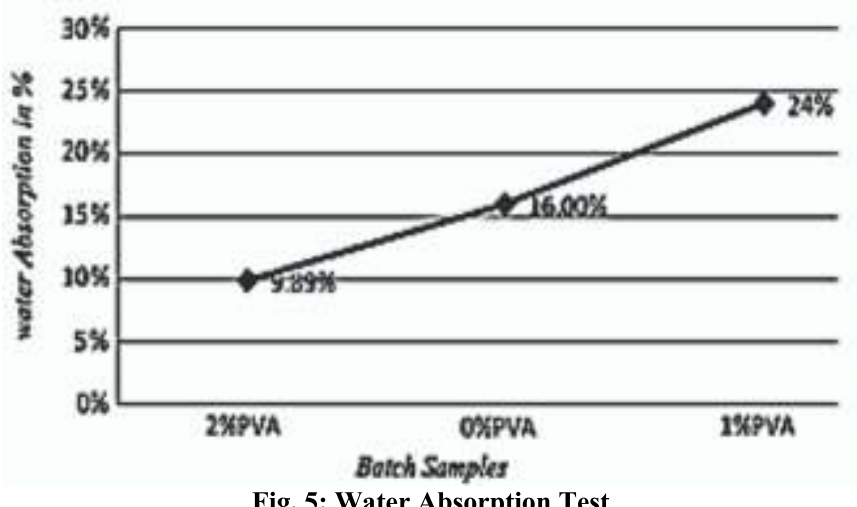

The experimental result of artificial aggregates was compared with natural aggregate as shown in the Table IV.

\begin{tabular}{|c|c|c|c|c|}
\hline \multirow{2}{*}{\begin{tabular}{|l|}
\multicolumn{1}{|c}{ Name of Test } \\
$\begin{array}{l}\text { Polyvinyl alcohol } \\
\text { (PVA) }\end{array}$
\end{tabular}} & \multicolumn{3}{|c|}{ Artificial aggregates } & \multirow{2}{*}{$\begin{array}{c}\text { Natural } \\
\text { Aggrega } \\
\text { tes }\end{array}$} \\
\hline & $\begin{array}{c}2 \% \\
\text { PVA }\end{array}$ & $\begin{array}{c}1 \% \\
\text { PVA }\end{array}$ & $\begin{array}{c}0 \% \\
\text { PVA }\end{array}$ & \\
\hline Water Absorption & $9.89 \%$ & $16 \%$ & $19.5 \%$ & $1.16 \%$ \\
\hline Sieve Analysis Test & F.M $=6.7$ & F.M $=6.96$ & F.M $=6.56$ & $\begin{array}{c}\text { F.M for all } \\
2-9\end{array}$ \\
\hline Impact $V_{s}$ & $27.75 \%$ & $34.30 \%$ & $40.15 \%$ & $14.72 \%$ \\
\hline Loss Angles Abrasion & $44 \%$ & $50 \%$ & $59.8 \%$ & $18 \%$ \\
\hline
\end{tabular}

\section{CONCLUSION AND FUTURE RECOMMENDATION}

The objective of this research project is to convert waste fines or silt, into aggregate and conserves landfill void space. Recycling of waste stone sludge and waste silt etc., for the production of artificial aggregate not only offers a feasible substitute for sand and stone, but also an ecological alternative to waste management of sludge and silt. Recycling is now becoming a business in many parts of the world.

Following are some of the key points based on this research:

- Los Angeles abrasion value of artificial aggregates is $44 \%$ which suggest it can be used in "Water bound macadam sub base course" for which limit is $60 \%$.

- The impact value of artificial aggregates is reasonable which will suggest that they can be used where they are to be subjected to repeated loadings.

- $\quad$ The bulk specific gravity of natural aggregate is 2.2 and the artificial aggregates which were prepared of bulk specific gravity are 1.53, therefore, the aggregates were suggested as a LWA.
- Sieve analysis of the artificial aggregates gives us a good result. The sample with $2 \%$, PVA contain moderate sizes of particles (both coarse and fine aggregate).

- Since artificial aggregates were produced synthetically, there is always room for improvement.

- Artificial aggregates produced can be used in the backfill, sub-base and for other non-structural uses.

- Voids in artificial aggregates must reduce by compaction, thus producing compacted artificial aggregates.

- Chemical properties of these artificial aggregates should be tested

- The strength of aggregates should be checked for other mix ratios of aggregate with higher watercement ratios and other additives.

- For resultsthat are more authentic, they should be subjected for use in the practical field as LWA.

- To get better results, advance and maintained equipment should be used.

- 28 days' compressive strength of these aggregates should be tested to see the effect of aging.

- This research can further be extended by the addition of fly ash or other binders to enhance different characteristics of the aggregates.

\section{REFERENCES}

[1] Lupo, R. et al.,(n.d.). Manufacture of Aggregates from Waste Silt and Fines.Department of Civil and Environmental Engineering, Imperial College, London. Retrieved from http://www.mtyrer.net/resources/silt2stone.pdf.

[2] Lampris, C., Lupo, R., \& Cheeseman, C. R. (2009). Geopolymerisation of silt produced from construction and demolition waste washing plants. Waste Management, 29(1), 368373.

[3] Chen, H. et al., (2012). Producing synthetic lightweight aggregates from reservoir sediments. Construction and Building Materials 28(1), 387-394.

[4] Wei, Y. et al., (2008). Recycling of harbor sediment as lightweight aggregate. Marine Pollution Bulletin, 57(12), 867-872.

[5] Strokova, V., et al., (2014). Artificial aggregates based on granulated reactive silica powders.Advanced Powder Technology, 25(3), 1076-1081.

[6] Gonza'lez-Corrochano, B. (2009). Manufacture of lightweight aggregates from mining and industrial wastes. Journal of Environmental Management, 90(1), 2801-2812.

[7] Bijen, J. M. J. M. (1986). Manufacturing processes of artificial lightweight aggregates from fly ash. The International Journal of Cement Composites and Lightweight Concrete, 8(3), 191-199.

[8] Chang, F. C. et al., (2010)Artificial aggregate made from wast e stone sludge and waste silt. Journal of environmental management, 91(11), 2289-2294. 